\title{
Isoprophylaxis is neither homeoprophylaxis nor homeopathic immunization, but isopathic immunization unsupported by the homeopathic epistemological model: a response to Golden
}

\author{
Marcus Zulian Teixeira
}

School of Medicine, University of São Paulo (FMUSP), São Paulo, Brazil

\begin{abstract}
Homeopathy might be employed for the prevention of epidemic diseases (homeoprophylaxis) provided remedies are selected on an individual basis in compliance with the principle of symptom-based similitude' and according to the totality of symptoms peculiar to a given epidemic (remedy of the 'epidemic genius' or 'genus epidemicus'), as countless examples in the literature show. The use of nosodes for the prevention of epidemic diseases (isoprophylaxis), i.e., selected based on the 'principle of etiological identity' with full neglect of symptom-based individualization and pathogenetic trials, is not supported by the homeopathic epistemological model. As long as there are no reliable scientific evidences attesting to its efficacy and safety, isopathic immunization' might not be indicated as a regular replacement of classical immunization, as it would mean a transgression of the bioethical principles of 'beneficence' and 'non-maleficence'. Although many homeopathic practitioners systematically indicate that practice, it is condemned by homeopathic institutions worldwide. In this article, I elaborate on epistemological, ethical and scientific features of these disparate approaches to prophylaxis, which I had summarily addressed in a previous review.
\end{abstract}

Keywords: Homeopathy; Promotion of health; Prevention of diseases; Prevention and control; Collective diseases; Epidemic genius; Isotherapy; Vaccination

\section{Introduction}

In 2009, I published a review on the therapeutic and preventive application of Hahnemann's homeopathy to epidemic diseases, according to which the selection of the 'constitutional' and 'epidemic genius' or 'genus epidemicus' (GE) remedies ought to be based on the 'principle of symptom-based similitude' ('homeopathic' and 'individualized'). On those grounds, I criticized the indiscriminate use of 'isopathic' medicines ('nosodes', 'isotherapic' or 'biotherapic' agents, which are selected according to the 'principle of etiological identity') as a standard prophylactic approach against epidemic diseases instead of classical immunization, for neglecting the epistemological premises of the traditional homeopathic model that underlie those century-old applications. In addition, I stressed the need to 'individualize' the GE remedies indicated for the treatment and/or prevention of each new epidemic outbreak of a same disease, as well as in function of their different stages [1]. 
Asserting that I "failed to fully understand the principle of similars", Isaac Golden criticizes my views in this issue of IJHDR [2], on the grounds that I "used a double standard when comparing evidence using GE remedies and nosodes", "misread information demonstrating the safety of long-term homoeoprophylaxis (HP)" and "appeared to be unaware of scientific evidence which is available supporting the prophylactic use of nosodes".

To substantiate my views, in that review I drew heavily on and quoted extensively from Hahnemann's Organon of Medicine [3] and Lesser Writings [4], which represent the backbone of the homeopathic epistemological model. However, it seems that Golden did not read my review, as many of the epistemological, scientific and ethical issues he disputes are thoroughly elucidated there [1].

For that reason, I thank the Editor of IJHDR the opportunity afforded to elaborate further on the epistemological, scientific and ethical aspects addressed in the previous review to show that the isoprophylactic program formulated by Golden has no support in the homeopathic epistemological model, and that its author does not provide scientific evidence attesting to its safety and effectiveness, and transgresses the bioethical aspects of "beneficence" and "non-maleficence".

\section{Epistemological premises of the homeopathic method of treatment}

The homeopathic method of treatment of (chronic, acute and epidemic) diseases is based on four fundamental premises or assumptions: 1) similarity of signs and symptoms between patient and remedy (principle of symptom-based similitude); 2) testing of remedies in humans (pathogenetic trials); 3) prescription of individualized remedies; and 4) use of potentized remedies. From these four basic assumptions, the use of potentized or dynamized (serially diluted and agitated) remedies is attributed particular relevance, although Hahnemann first formulated it to minimize the occurrence of eventual aggravations. The foundations of the epistemological model of Hahnemann's homeopathy are provided by the former two, i.e., therapeutic similarity and pathogenetic trials of drugs, while therapeutic individualization (based on the 'totality of characteristic signs and symptoms') is the inherent condition that allows for the curative (preventive) reaction of the organism to be effectively awakened $[1,5]$.

As it is known, those assumptions are explained in several paragraphs of Organon of Medicine in the simple, clear and free from contradiction style that characterizes Hahnemann's reasoning. In my previous review, I quoted and commented briefly Hahnemann's assertions, here I present further elaboration to make them more easily understandable.

\section{Principle of symptom-based similitude (law of similars)}

In Organon of Medicine § 6-12 [3], Hahnemann attributes the cause of any disease to an imbalance of the vital force' ("morbid derangement of the internal dynamis"), which is revealed to us by the 'totality of manifested signs and symptoms' ("morbid phenomena perceptible to our senses"). By the same token, the cure of diseases ("recovered health of the whole organism") occurs through the "restoration of the integrity of the vital force", resulting in the "disappearance under treatment of all the morbid phenomena".

"It is the morbidly affected vital energy alone that produces diseases, so that the morbid phenomena perceptible to our senses express at the same time all the internal change, that is to say, the whole morbid derangement of the internal dynamis; in a word, they reveal the whole disease; consequently, also, the disappearance under treatment of all the morbid phenomena and of all the morbid alterations that differ from the healthy vital operations, certainly affects and necessarily implies the restoration of the integrity of the vital force and, therefore, the recovered health of the whole organism." (Organon of Medicine, § 12) 
Due to the "futility of transcendental speculation which can receive no confirmation from experience", Hahnemann had no interest whatsoever in investigating "how the vital force causes the organism to display morbid phenomena, that is, how it produces disease", as "it would be of no practical utility to the physician to know" (Organon of Medicine, $\S 6$ note to $\S 12$ ). Other homeopaths sought to explain the principle of therapeutic similarity by appealing to 'metaphysical' notions, but Hahnemann remained highly critical of such endeavors to prioritize the more practical and scientific approaches (phenomenological qualitative research) that in time proved to be crucial for the survival of the homeopathic model along more than two centuries. In Organon of Medicine, $\S 14-18$, he reiterates that the diagnosis of the vital force imbalance and of all diseases "makes itself known to the accurately observing physicians by means of morbid signs and symptoms".

"From this indubitable truth, that besides the totality of the symptoms with consideration of the accompanying modalities ( $§ 5)$ nothing can by any means be discovered in disease wherewith they could express their need of aid, it follows undeniably that the sum of all the symptoms and conditions in each individual case of disease must be the sole indication, the sole guide to direct us in the choice of a remedy." (Organon of Medicine, § 18)

In $\S 19-22$, Hahnemann highlights the relevance of the 'pathogenetic trials of substances in humans', as doctors can only learn the curative properties of drugs from the "totality of signs and symptoms [they] cause in the state of men's health". Once a doctor learns the type of symptoms that substances arouse in experimental subjects (similar or opposite to the symptoms of the disease to treat), he or she will be able to indicate a similar (homeopathic) or opposite (enantiopathic) treatment.

"But as nothing is to be observed in diseases that must be removed in order to change them into health besides the totality of their signs and symptoms, and likewise medicines can show nothing curative besides their tendency to produce morbid symptoms in healthy persons and to remove them in diseased persons; it follows, on the one hand, that medicines only become remedies and capable of annihilating disease, because the medicinal substance, by exciting certain effects and symptoms, that is to say, by producing a certain artificial morbid state, removes and abrogates the symptoms already present, to wit, the natural morbid state we wish to cure. On the other hand, it follows that, for the totality of the symptoms of the disease to be cured, a medicine must be sought which (according as experience shall prove whether the morbid symptoms are most readily, certainly, and permanently removed and changed into health by similar or opposite medicinal symptoms) have the greatest tendency to produce similar or opposite symptoms." (Organon of Medicine, § 22)

As the "persistent symptoms of disease are far from being removed and annihilated by opposite symptoms of medicines (as in the antipathic, enantiopathic or palliative method), that, on the contrary, after transient, apparent alleviation, they break forth again, only with increased intensity, and become manifestly aggravated" (Organon of Medicine, $\S 23,58-62,69)$, Hahnemann recommends the 'homeopathic method of treatment', "by means of which we seek, for the totality of the symptoms of the case of disease, a medicine which among all medicines (whose pathogenetic effects are known from having been tested in healthy individuals) has the power and the tendency to produce an artificial morbid state most similar to that of the case of disease in question" (Organon of Medicine, § 24-29).

"Now, however, in all careful trials, pure experience, the sole and infallible oracle of the healing art, teaches us that actually that medicine which, in its action on the healthy human body, has demonstrated its power of producing the greatest number of symptoms similar to those observable in the case of disease under treatment, does also, in doses of suitable potency and attenuation, rapidly, radically and permanently remove the totality of the symptoms of this morbid state, that is to say (§ 6-16), the whole disease present, and change 
it into health; and that all medicines cure, without exception, those diseases whose symptoms most nearly resemble their own, and leave none of them uncured." (Organon of Medicine, § 25)

"The curative power of medicines, therefore, depends on their symptoms, similar to the disease but superior to it in strength (§ 12-26), so that each individual case of disease is most surely, radically, rapidly and permanently annihilated and removed only by a medicine capable of producing (in the human system) in the most similar and complete manner the totality of its symptoms, which at the same time are stronger than the disease." (Organon of Medicine, § 27)

In Organon of Medicine § 63, Hahnemann outlines a physiological explanation of the 'mechanism of action' of the principle of therapeutic similitude employed in the homeopathic method of treatment: "Every agent that acts upon the vitality, every medicine, deranges more or less the vital force, and causes a certain alteration in the health of the individual for a longer or a shorter period. This is termed primary action. [...] To its action our vital force endeavors to oppose its own energy. This resistant action is a property, is indeed an automatic action of our life-preserving power, which goes by the name of secondary action or counteraction".

Hahnemann describes several examples of that universal mechanism of action of drugs (primary action of the drug followed by secondary and opposite action of the organism) in association with the physiological effects of various palliative (enantiopathic) treatments used in his time.

"[...] Excessive vivacity follows the use of strong coffee (primary action), but sluggishness and drowsiness remain for a long time afterwards (reaction, secondary action), if this be not always again removed for a short time by imbibing fresh supplies of coffee (palliative). After the profound stupefied sleep caused by opium (primary action), the following night will be all the more sleepless (reaction, secondary action). After the constipation produced by opium (primary action), diarrhoea ensues (secondary action); and after purgation with medicines that irritate the bowels, constipation of several days' duration ensues (secondary action). And in like manner it always happens, after the primary action of a medicine that produces in large doses a great change in the health of a healthy person, that its exact opposite, when, as has been observed, there is actually such a thing, is produced in the secondary action by our vital force." (Organon of Medicine, § 65)

The homeopathic model of treatment profits from the secondary action (vital reaction) of the organism as a therapeutic means. By administering to ill individuals substances that were proven to cause a similar 'totality of characteristic symptoms and signs' (similia similibus curentur), homeopaths seek to awaken an effective and healing vital reaction of the organism against its own disorders, thus restoring its normal state of health. It is worth mentioning for the sake of future discussions, that only an 'effective vital reaction' able to stimulate the organism's various physiological systems (mental, neurological, immune, endocrine, metabolic systems, etc.) via the "characteristic totality of symptoms" might induce effective curative and preventive actions.

By emphasizing that the organism's secondary action (opposite in character to the primary action of the drug) occurs "in all cases, without exception", i.e., with ponderable or infinitesimal doses, in healthy or ill individuals, Hahnemann raised the principle of similarity to the category of a 'natural law' (Organon, § 58, 61, 110-112).

"In those older prescriptions of the often dangerous effects of medicines ingested in excessively large doses we notice certain states that were produced, not at the commencement, but towards the termination of these sad events, and which were of an exactly opposite nature to those that first appeared. These symptoms, the very reverse of the primary action (§63) or proper action of the medicines on the vital force are the reaction of the vital force of the organism, its secondary action (§ 62-67), of which, however, there is seldom or hardly ever the least trace from experiments with moderate doses on healthy bodies, and from small doses none whatever. 
In the homoeopathic curative operation the living organism reacts from these only so much as is requisite to raise the health again to the normal healthy state (§ 67).” (Organon of medicine, $\S 112)$

In the terms of contemporary scientific reason and physio-pharmacological notions, the "primary action" mentioned by Hahnemann corresponds to the 'therapeutic, adverse and side effects' of conventional drugs. The "secondary action" or "vital reaction", in turn, corresponds to the 'rebound effect' or 'paradoxical reaction' of the organism, which occurs after the discontinuation of several classes of drugs that act contrarily to the symptoms of diseases (modern enantiopathic drugs) [6-17]. Just as the homeopathic drugs (similar to the 'totality of characteristic symptoms') awaken a curative vital reaction in a small number of idiosyncratic individuals only, also the rebound effect of modern drugs is an idiosyncratic property and thus, it appears in a small fraction of individuals only. The evidences afforded by modern pharmacology provide scientific support to the inclusion of 'therapeutic individualization' among the epistemological foundations of the homeopathic model.

\section{Homeopathic pathogenetic experimentation (trials)}

As mentioned above, the 'second epistemological premise' ("second point of the business of a true physician" according to Hahnemann) concerns the investigation of the pathogenetic properties of drugs, the knowledge of which is a sine qua non condition for the application of the principle of therapeutic similitude. For that purpose, a model of clinical-pharmacological studies, similar to phase I modern pharmacological preclinical trials, but serving the particular requirements of homeopathic practice, was designed, to wit, the so-called 'homeopathic pathogenetic experimentation' or 'homeopathic pathogenetic trial' (HPT). HPTs take all kinds of signs and symptoms (mental, general and physical) elicited by the tested substances into account, no matter whether they were administered in mass- or infinitesimal doses, and that correspond to the therapeutic, adverse and side-effects of modern drugs.

"The second point of the business of a true physician related to acquiring a knowledge of the instruments intended for the cure of the natural diseases, investigating the pathogenetic power of the medicines, in order, when called on to cure, to be able to select from among them one, from the list of whose symptoms an artificial disease may be constructed, as similar as possible to the totality of the principal symptoms of the natural disease sought to be cured." (Organon of Medicine, § 105)

"The whole pathogenetic effect of the several medicines must be known; that is to say, all the morbid symptoms and alterations in the health that each of them is specially capable of developing in the healthy individual must first have been observed as far as possible, before we can hope to be able to find among them, and to select, suitable homoeopathic remedies for most of the natural diseases." (Organon of medicine, § 106)

All the pathogenetic symptoms collected in HPTs are compiled in the homeopathic materia medica following an anatomical-functional distribution (mind, head, eyes, ears, nose, face, mouth, throat, stomach, abdomen, etc.). In clinical practice, homeopaths select 'individualized homeopathic medicines' based on the 'totality of characteristic symptoms' exhibited by patients. This the safest and most effective approach to the prescription of 'medicines able to cause morbid symptoms (adverse effects) in humans', which is the basic requirement for the application of the principle of symptom-based similitude: "medicines can show nothing curative besides their tendency to produce morbid symptoms in healthy persons and to remove them in diseased persons" (Organon of medicine, § 22).

\section{Individualized treatment with simple substances}

According to Hahnemann, any doctor aspiring to become a "genuine artist of healing" should be able to recognize that which must be healed in each individual case of disease, understand the healing properties of 
remedies and adjust them qualitatively and quantitatively to the patient's needs according to the principle of therapeutic similitude (Organon of Medicine, § 3).

As Hahnemann conceived of illness as a weakened operation of the normal physiological processes of adjustment and compensation, he associated any internal imbalance with the various individual symptomatic manifestations. As a consequence, he employed the "totality of signs and symptoms" exhibited by patients as the basic criterion for diagnosis of the "affection of the vital force" (individual predisposition, morbid susceptibility or homeostatic imbalance) and selection of the homeopathic remedy most similar to the condition exhibited by the ill individual.

"Now, as in a disease [...] we can perceive nothing but the morbid symptoms, it must [...] be the symptoms alone by which the disease demands and points to the remedy suited to relieve it - and, moreover, the totality of these its symptoms, of this outwardly reflected picture of the internal essence of the disease, that is, of the affection of the vital force, must be the principal, or the sole means, whereby the disease can make known what remedy it requires - the only thing that can determine the choice of the most appropriate remedy - and thus, in a word, the totality of the symptoms must be the principal, indeed the only thing the physician has to take note of in every case of disease and to remove by means of his art, in order that it shall be cured and transformed into health." (Organon of Medicine, § 7)

From the set of patent signs and symptoms exhibited by patients, homeopathic semiology emphasizes the "more striking, singular, uncommon and peculiar (characteristic)" in each case of disease (idiosyncratic aspects), while it dismisses the common, generic and indefinite symptoms as lacking inherent individualizing power.

"In this search for a homoeopathic specific remedy, that is to say, in this comparison of the collective symptoms of the natural disease with the list of symptoms of known medicines, in order to find among these an artificial morbific agent corresponding by similarity to the disease to be cured, the more striking, singular, uncommon and peculiar (characteristic) signs and symptoms of the case of disease are chiefly and most solely to be kept in view; for it is more particularly these that very similar ones in the list of symptoms of the selected medicine must correspond to, in order to constitute it the most suitable for effecting the cure. The more general and undefined symptoms: loss of appetite, headache, debility, restless sleep, discomfort, and so forth, demand but little attention when of that vague and indefinite character, if they cannot be more accurately described, as symptoms of such a general nature are observed in almost every disease and from almost every drug." (Organon of medicine, § 153)

"If, however, among the symptoms of the remedy selected, there be none that accurately resemble the distinctive (characteristic), peculiar, uncommon symptoms of the case of disease, and if the remedy correspond to the disease only in the general, vaguely described, indefinite states (nausea, debility, headache, and so forth), and if there be among the known medicines none more homoeopathically appropriate, in that case the physician cannot promise himself any immediate favorable result from the employment of this unhomoeopathic medicine." (Organon of Medicine, § 165)

"We shall, therefore, never be able to cure conformably to nature - that is to say, homoeopathically - if we do not, in every case of disease, even in such as are acute, observe, along with the other symptoms, those relating to the changes in the state of the mind and disposition, and if we do not select, for the patient's relief, from among the medicines a disease-force which, in addition to the similitude of its other symptoms to those of the disease, is also capable of producing a similar state of the disposition and mind." (Organon of Medicine, § 213) 
As a result of the combination of the principle of symptom-based therapeutic individualization and the injunction to prescribe "one single, simple medicinal substance at one time", Hahnemann was adamantly against the simultaneous use of more than one homeopathic remedy (a premise that is dismissed by many homeopaths) on the grounds that the HPTs were conducted with single and simple substances. By the same token, he condemned the use of composite means (remedy mixtures or so-called 'homeopathic complexes') without subjecting them to HPTs first.

"In no case under treatment it is necessary and therefore not permissible to administer to a patient more than one single, simple medicinal substance at one time. It is inconceivable how the slightest doubt could exist as to whether it was more consistent with nature and more rational to prescribe a single, simple medicine at one time in a disease or a mixture of several differently acting drugs. It is absolutely not allowed in homoeopathy, the one true, simple and natural art of healing, to give the patient at one time two different medicinal substances.” (Organon of Medicine, § 273)

"As the true physician finds in simple medicines, administered singly and uncombined, all that he can possibly desire [...] he will, mindful of the wise maxim that it is wrong to attempt to employ complex means when simple means suffice, never think of giving as a remedy any but a single, simple medicinal substance; for these reasons also, because even though the simple medicines were thoroughly proved with respect to their pure peculiar effects on the unimpaired healthy state of man, it is yet impossible to foresee how two and more medicinal substances might, when compounded, hinder and alter each other's actions on the human body [...]." (Organon of Medicine $\S 274)$

To summarize, a proper homeopathic treatment prioritizes an 'individualized choice of a single remedy based on the most characteristic signals and symptoms exhibited by the patient' across the various fields of clinical expression (i.e., mental, general and physical). As a consequence, different remedies might be prescribed to individuals with a same disease as a function of their singular pattern of susceptibility (including physical, mental, emotional, dietary and weather-related components, among many others). In addition to being the 'most effective', it is also the 'safest' approach to avoid the occurrence of adverse events that the homeopathic remedies (pathogenetic effects) are liable to cause in susceptible individuals [18, 19].

As stated in my previous review [1], the homeostatic balance of the mental, general and physical functions achieved through the application of the principle of symptom-based similitude contributes to the promotion of health, and thus constitutes a preventive means against disease by itself. According to the traditional homeopathic model, this is the most effective means to induce immunity against all epidemics.

As Hahnemann emphasized, any remedy selected without complying with this 'third homeopathic epistemological premise' (symptom-based individualization) should be considered as "unhomeopathic medicine" and will not elicit a "favorable result" nor "effecting the cure" [5]. This is to say, all three epistemological assumptions discussed up to this point should be complied with for any therapeutic or preventive action to earn the right to prefix "homeo".

\section{Potentized (dynamized) remedies (high dilutions or infinitesimal doses)}

In the early years of homeopathy, Hahnemann applied the 'principle of symptom-based similitude' using 'substantial doses' of drugs selected as a function of the 'pathogenetic symptoms' they had elicited on healthy or ill individuals. On these grounds, he performed successful treatments of a wide variety of chronic, acute and epidemic diseases, which are described in his Essay on a new principle for ascertaining the curative power of drugs [20], published in 1796, to wit: uterine colic with Matricaria chamomilla; autumnal dysentery with Arnica montana; painful indurations of the lymph nodes with Conium maculatum; paralytic and spasmodic affections with Solanum dulcamara; chronic hemorrhages, mania and seizures with Hyosciamus niger; 
tremors, muscle twitching, cramps and intermittent fevers with Ignatia amara; amaurosis, cataracts and opacities of the cornea with Anemona pratensis, among others.

In 1799, during an epidemic of scarlet fever [21], Hahnemann used 'diluted and agitated doses' for the first time to reduce the pathogenetic power of the medication and thus avoid the occurrence of 'aggravations' [22]. In 1814, during the treatment of typhus or hospital fever [23], Hahnemann outlined the method of potentization (serial dilutions with strong agitation), while the 'theory of potentization' in strict sense only is formulated in 1827 [24], when Hahnemann incorporated trituration and succussion in the 'potentization process' to develop and exalt the "dynamic medicinal powers of natural substances". However, even after having provided sound foundations to his 'theory of potentization', Hahnemann continued prescribing remedies in ponderable doses for the treatment or prevention of diseases [25, 26], as well as in pathogenetic studies.

"The homoeopathic system of medicine develops for its special use, to a hitherto unheard-of degree, the inner medicinal powers of the crude substances by means of a process peculiar to it and which has hitherto never been tried, whereby only they all become immeasurably and penetratingly efficacious and remedial, even those that in the crude state give no evidence of the slightest medicinal power on the human body. This remarkable change in the qualities of natural bodies develops the latent, hitherto unperceived, as if slumbering hidden, dynamic powers which influence the life principle, change the well-being of animal life. This is effected by mechanical action upon their smallest particles by means of rubbing and shaking and through the addition of an indifferent substance, dry of fluid, are separated from each other. This process is called dynamizing, potentizing (development of medicinal power) and the products are dynamizations or potencies in different degrees." (Organon of Medicine, § 269)

Therefore, it is worth to emphasize that although 'dynamizing or potentizing' increases the "medicinal powers of the crude substances", thus enlarging the scope of safety and efficacy of remedies, a homeopathic treatment might also be conducted using 'ponderable doses' (i.e., not potentized), provided the first three epistemological premises are complied with. By the same token, mere indication of 'potentized remedies' with disregard for those three premises might not be considered as a homeopathic treatment, as e.g., it is the case of isopathy.

\section{Epistemological premises of the homeopathic method of treatment (prevention) in epidemic diseases}

As mentioned in my original review [1], the epistemological premises underlying the treatment of epidemic diseases are the same as in other (acute and chronic) diseases, i.e., based on the present 'characteristic totality of symptoms' (as in the acute diseases), as described in several paragraphs of Organon of Medicine.

\section{Hahnemann's guidelines - Use of the remedy of the "epidemic genius"}

As in the case of acute and chronic diseases discussed above, Hahnemann also laid down individualizing semiologic and therapeutic guidelines for the approach to epidemic diseases. Just as each individual patient exhibits a set of characteristic signs and symptoms that distinguishes him or her from all other individuals with the same acute or chronic disease, also each epidemic disease "is a phenomenon of unique character" that must be distinguished from all previous outbreaks. Hahnemann, thus, warns against the application of information obtained in past outbreaks to future ones without a "careful examination of the pure picture of the prevailing disease". 
"In investigating the totality of the symptoms of epidemic and sporadic diseases it is quite immaterial whether or not something similar has ever appeared in the world before under the same or any other name. The novelty or peculiarity of a disease of that kind makes no difference either in the mode of examining or of treating it, as the physician must any way regard to pure picture of every prevailing disease as if it were something new and unknown, and investigate it thoroughly for itself, if he desire to practice medicine in a real and radical manner, never substituting conjecture for actual observation, never taking for granted that the case of disease before him is already wholly or partially known, but always carefully examining it in all its phases; and this mode of procedure is all the more requisite in such cases, as a careful examination will show that every prevailing disease is in many respects a phenomenon of a unique character, differing vastly from all previous epidemics, to which certain names have been falsely applied [...].” (Organon of Medicine, § 100)

As in all collective diseases the pathological image might only emerge after having observed a considerable number of individuals, Hahnemann indicates to observe several cases to paint "the full picture of the disease", "totality of signs and symptoms" or 'epidemic genius', according to the homeopathic connotation of this notion.

"It may easily happen that in the first case of an epidemic disease that presents itself to the physician's notice he does not at once obtain a knowledge of its complete picture, as it is only by a close observation of several cases of every such collective disease that he can become conversant with the totality of its signs and symptoms. The carefully observing physician can, however, from the examination of even the first and second patients, often arrive so nearly at a knowledge of the true state as to have in his mind a characteristic portrait of it, and even to succeed in finding a suitable, homoeopathically adapted remedy for it." (Organon of Medicine, § 101)

When searching for the remedy of the 'epidemic genius', one should bear in mind that the "characteristic picture of the epidemic" will emerge from the "totality of the most peculiar, rare and uncommon signs and symptoms'. The thus 'individualized remedy' might then be therapeutically prescribed to all the individuals affected by a same outbreak.

"In the course of writing down the symptoms of several cases of this kind the sketch of the disease picture becomes ever more and more complete, not more spun out and verbose, but more significant (more characteristic), and including more of the peculiarities of this collective disease; on the one hand, the general symptoms (e.g., loss of appetite, sleeplessness, etc.) become precisely defined as to their peculiarities; and on the other, the more marked and special symptoms which are peculiar to but few diseases and of rarer occurrence, at least in the same combination, become prominent and constitute what is characteristic of this malady. All those affected with the disease prevailing at a given time have certainly contracted it from one and the same source and hence are suffering from the same disease; but the whole extent of such an epidemic disease and the totality of its symptoms (the knowledge whereof, which is essential for enabling us to choose the most suitable homoeopathic remedy for this array of symptoms, is obtained by a complete survey of the morbid picture) cannot be learned from one single patient, but is only to be perfectly deduced (abstracted) and ascertained from the sufferings of several patients of different constitutions." (Organon of Medicine, § 102)

Upon reflecting on the nature and treatment of epidemics of intermittent fever (Organon of Medicine, § 235244), Hahnemann restates the need to individualize the "homoeopathic (specific) remedy suitable for all the cases" (epidemic genius) for the ongoing clinical manifestations according to the "totality of symptoms common to all". With patent coherence, Hahnemann stresses the epistemological premise indicating the use of simple and single (specific) substances and avoidance of complex means.

"With regard to the intermittent fevers, that prevail sporadically or epidemically (not those endemically located in marshy districts), we often find every paroxysm likewise composed of two opposite alternating states (cold, heat - heat, cold), more frequently still of three (cold, heat, sweat). Therefore the remedy selected 
for them from the general class of proved (common, not antipsoric) medicines must either (and remedies of this sort are the surest) be able likewise to produce in the healthy body two (or all three) similar alternating states, or else must correspond by similarity of symptoms, in the most homoeopathic manner possible, to the strongest, best marked, and most peculiar alternating state (either to the cold stage, or to the hot stage, or to the sweating state, each with its accessory symptoms, according as the one or other alternating state is the strongest and most peculiar); but the symptoms of the patient's health during the intervals when he is free from fever must be the chief guide to the most appropriate homoeopathic remedy." (Organon of Medicine, $\S$ 235)

"Epidemics of intermittent fever, in situations where none are endemic, are of the nature of chronic diseases, composed of single acute paroxysms; each single epidemic is of a peculiar, uniform character common to all the individuals attacked, and when this character is found in the totality of the symptoms common to all, it guides us to the discovery of the homoeopathic (specific) remedy suitable for all the cases, which is almost universally serviceable in those patients who enjoyed tolerable health before the occurrence of the epidemic, that is to say, who were not chronic sufferers from developed psora." (Organon of Medicine, § 241)

As mentioned in the original article [1], in addition to indicating homeopathic remedies as therapeutic means for manifest cases of epidemic diseases, Hahnemann also points to the use of individualized homeopathic medicines' as a 'prophylactic practice'. In this regard, he mentions the example of Atropa belladonna, which had cured individuals affected by scarlet fever in previous epidemics, as preventive remedy for future similar epidemic outbreaks. It is worth to call the attention to the fact that the same homeopathic approach based on the "totality of symptoms common to all" (epidemic genius) was used in the selection of preventive remedies for each stage of disease.

"A striking fact in corroboration of this is, that whilst previously to the year 1801, when the smooth scarlatina of Sydenham still occasionally prevailed epidemically among children, it attacked without exception all children who had escaped it in a former epidemic; in a similar epidemic which I witnessed in Konigslutter, on the contrary, all the children who took in time a very small dose of Belladonna remained unaffected by this highly infectious infantile disease. If medicines can protect from a disease that is raging around, they must possess a vastly superior power of affecting our vital force." (Organon of Medicine, note to § 33)

"Subsequently to the year 1801 a kind of purpura miliaris (roodvonk), which came from the West, was by physicians confounded with the scarlet fever, notwithstanding that they exhibited totally different symptoms, that the latter found its prophylactic and curative remedy in belladonna, the former in aconite, and that the former was generally merely sporadic, while the latter was invariable epidemic. Of late years it seems as if the two occasionally joined to form an eruptive fever of a peculiar kind, for which neither the one nor the other remedy, alone, will be found to be exactly homoeopathic.” (Organon of Medicine, note to § 73)

This prophylactic use Hahnemann made of Atropa belladonna in epidemics of scarlet fever is insistently mentioned by Golden, inappropriately, to justify prophylaxis in general (including isoprophylaxis). In a biased manner, he uses the "homeopathic" evidence (resulting from the use of remedies chosen as a function of their similarity with the 'symptom-based epidemic genius') to justify his 'isopathic practice' (i.e., based in 'nosodes' chosen based on their identity with 'etiologic agents'), thus confusing readers unaware of the differences between both. By mixing together those different approaches, Golden has recourse in several of his conclusive statements on the effectiveness of isoprophylaxis ("there is a growing body of rigorous scientific evidence supporting the effectiveness of homoeopathic immunisation whether using GE remedies or nosodes") [2] to the robust century-old evidences for the application of GE remedies to make up for the poor evidence relative to the use of nosodes. 
According to Hahnemann and the homeopathic epistemological model, 'prevention' is only possible when the selected remedy is chosen according to 'epidemic genius' criteria and is similar to the totality of characteristic symptoms of the "early stage of the epidemic" ("a remedy that is capable of quickly checking a disease in its onset, must be its best preventive") [21,27]. Here it is worth to remind that Hahnemann prescribed different remedies for each stage of an epidemic disease, which were systematically individualized as a function of the corresponding symptoms. This is a sine qua non condition for GE remedies to have effective prophylactic action in any epidemic, and thus it should be systematically taken into consideration in the selection of such remedies.

In a short work entitled "Cure and Prevention of Scarlet Fever" [21], Hahnemann describes the use of Atropa belladona for the prevention and treatment of the early stage of an epidemic that occurred in Königslutter in 1799. That remedy had been chosen as a function of the GE of that particular stage the disease, as according to him, "a remedy that is capable of quickly checking a disease in its onset, must be its best preventive". Here he also describes the use of Opium and Ipeca for the treatment of two different conditions presenting in the stage of full development of disease. Those remedies were prescribed alone or in alternation as a function of the state exhibited by each individual patient and the set of symptoms corresponding to each manifestation of disease: "For my own part, when summoned to cases of the fully developed disease (where there was no question of prevention or suppressing its commencement), I found I had to combat two different states of body that sometimes rapidly alternated with one another, each of which was composed of a convolute of symptoms". He also mentions the use of Matricaria chamomilla for what he describes as "unhealthy skin" and "the characteristic suffocating cough" that may appear in the course of scarlet fever. ([1], pages 162-163)

A similar procedure is described in two short writings on the treatment and prevention of Asian cholera [25, 26], in which Hahnemann indicates camphor as the GE remedy for the first stage of disease, particularly aiming at the prevention of its transmission (prophylactic approach). Due to the extremely short duration of that first stage (two hours), Hahnemann observed that in some cases "this first stage, with its tonic spasmodic character, is hardly observable, and the disease passes instantly into the second stage of clonic spasmodic character", when copper becomes the GE remedy for prevention, being representative of the "early stage of the epidemic".

"A receipt has been given to the world, which proved so efficacious in Dünaburg in the Asiatic cholera, that of ten patients but one died. The chief ingredient is camphor [...], and the camphor been given alone, and always at the very commencement of the disease, for it is only when given alone, and at the first invasion of the disease that it is so marvelously useful. But if physicians come, as usual, too late to the patient, when the favorable time for employing the camphor is past, and the second stage has already set in, when camphor is useless, then they may use it in vain; their patients will die under its employment. Hence every one, the instant any of his friends take ill of cholera, must himself immediately treat them with camphor, and not wait for medical aid, which, even if it were good, would generally come too late.

I have received many communications from Hungary from non-medical persons, who have restored their friends, as if by magic, by giving camphor the instant became ill. Where the cholera first appears, it usually comes on in the commencement in its first stage (with tonic spasmodic character); [...] In the first stage camphor gives rapid relief, but the patient's friends must themselves employ it, as this stage soon ends either in death or in the second stage, which is more difficult to be cured, and not with camphor. [...] If this period of the commencement of the disease, so favorable to recovery and speedy cure, by the above indicated employment of camphor, has been neglected, then things look worse; then camphor is no longer serviceable. There are moreover cases of cholera, especially in northern region, where this first stage, with its tonic spasmodic character, is hardly observable, and the disease passes instantly into the second stage of clonic spasmodic character; [...] The patient is to get one or two globules of the finest preparation of copper 
(prepared from metallic copper in the mode described in the second part of my work on Chronic Diseases) [...]." [25]

"If physicians would but take warning, and, rendered uninfectable by taking a few drops of camphorated spirit, approach (ever so quickly) the cholera patient, in order to treat him at the commencement of his sickening with this medicine (pure, unadulterated camphorated spirit) which alone is efficacious, and which most certainly destroys the miasm about the patient, by giving him, as I have taught, every five minutes one drop of it [...]. Thus, the cholera is most surely and easily and almost miraculously curable, but only in the first couple of hours from the commencement of the sickening, by means of the employment of pure camphor, and that before the physicians in larger towns that are summoned can attend. But on their arrival they may even then, by the employment of unadulterated camphor-spirit, if not cure the cholera completely (for the lapse of a few hours generally makes it too late to do so) yet annihilate the whole of the contagious principle of this pestilence on and about the patient, and adhering to themselves and the bystanders, and cease to convey the miasm with them to other parts of the town.” [26]

Based on the abovementioned considerations, there can be no doubt that the therapeutic and preventive approach to epidemic diseases according to the homeopathic epistemological model is one and the same and similar to the one applied to other acute and chronic diseases (albeit with some minor adjustments). It consists in the identification of the similarity between the totality of characteristic symptoms exhibited by a 'group of patients' and the pathogenetic manifestations of substances as described in the homeopathic materia medica to choose a simple and individualized remedy for each stage of disease.

As I observed in my original review [1], also James Tyler Kent used that same approach to the treatment of epidemic diseases. However, as Golden drew heavily from Kent to substantiate his misguided explanations, I discuss the latter's views more thoroughly in the next section.

\section{Kent's guidelines - Use of the remedy of the "epidemic genius"}

Based on Hahnemann's premises, Kent describes in Lectures on Homoeopathic Philosophy, Lecture 3, a semiologic protocol to diagnose the "group of epidemic remedies" (epidemic genius) [28]. Here he indicates to begin by observing 20 individuals affected by an epidemic disease very carefully and to record all their symptoms in a schematic manner (repertory classification) so that when addressed collectively they "present one image, as if one man had expressed all the symptoms". By placing before each symptom the number of patients that exhibited it, the homeopathic practitioner becomes able to "find out the essential features of the epidemic" (nature of the disease) based on the common (pathognomonic symptoms) and characteristic (peculiar symptoms) totality of symptoms.

Next, with the help of a homeopathic repertory, he or she should select 6 or 7 remedies that cover the totality of symptoms of the given epidemic (group of epidemic remedies) and refine the individual image of each remedy by checking their description in the homeopathic materia medica. Then, going from the general to the particular - as "there is no other way to proceed in homeopathy" - he or she should adjust the characteristics of each patient to the particularities of each selected remedy (individualization), as "a little difference in each case" is found even among the members of one same family. Were none of the thus selected remedies to be useful, "the physician must return to his original anamnesis to see which one of the other remedies is suitable". Kent emphasizes that although the application of the epidemic genius to the choice of homeopathic remedies demands hard work, its results are spectacular.

"[...] Every remedy has in itself a certain state of peculiarities that identifies it as an individual remedy, and the patient has also a certain state of peculiarities that identifies him as an individual patient, and so the remedy is fitted to the patient. No remedy must be given because it is in the list, for the list has only been 
made as a means of facilitating the study of that epidemic. Things can only be made easy by an immense amount of hard work, and if you do the drudgery in the beginning of an epidemic, the prescribing for your cases will be rapid, and you will find your remedies abort cases of sickness, make malignant cases simple, so simplify scarlet fever that classification would be impossible, stop the course of typhoids in a week, and cure remittent fevers in a day." (Lectures on Homoeopathic Philosophy, Lecture 3)

\section{Isoprophylaxis is neither homeoprophylaxis nor homeopathic immunization, but isopathic immunization unsupported by the homeopathic epistemological model}

Although he acknowledged the benefits afforded by the smallpox vaccine - which was introduced by Edward Jenner in 1796, after careful observation and description of a series of 27 immunized cases - Hahnemann condemned the indiscriminate use of high dilutions of parts or subproducts of a disease or pathogenic agent (nosodes or biotherapics) for prophylactic purposes or as isopathic treatment ('principle of etiological identity'; aequalia aequalibus curentur) without previous pathogenetic testing and application of similarity grounded on symptom-based individualization. According to Hahnemann, cowpox could be used as a homeopathic remedy only because its set of symptoms (disease) was similar to the one of smallpox.

"A third mode of employing medicines in diseases has been attempted to be created by means of Isopathy, as it is called - that is to say, a method of curing a given disease by the same contagious principle that produces it. [...] To attempt to cure by means of the very same morbific potency (per Idem) contradicts all normal human understanding and hence all experience. Those who first brought Isopathy to notice, probably thought of the benefit which mankind received from cowpox vaccination by which the vaccinated individual is protected against future cowpox infection and as it were cured in advance. But both, cowpox and smallpox are only similar, in no way the same disease. In many respects they differ, namely in the more rapid course and mildness of cowpox and especially in this, that is never contagious to man by more nearness. Universal vaccination put an end to all epidemics of that deadly fearful smallpox to such an extent that the present generation does no longer possess a clear conception of the former frightful smallpox plague. Moreover, in this way, undoubtedly, certain diseases peculiar to animals may give us remedies and thus happily enlarge our stock of homoeopathic remedies. But to use a human morbific matter (a Psorin taken from the itch in man) as a remedy for the same itch or for evils arisen therefrom is - ? Nothing can result from this but trouble and aggravation of the disease." (Organon of Medicine, note to § 56)

"It is only in accordance with my well known maxim (the new principle) that small-pox, to give one example from among many, has an important prophylactic in the cow-pox, which is an exanthematous disease, whose pustules break out after the sixth day of inoculation, with pain and swelling of the axillaries glands, pain in the back and loins, and fever, and surrounded by an erythematous inflammation - that is to say, constituting altogether a disease very similar to variola." [21]

As it was discussed above, for any substance (simple or complex) to be considered as a homeopathic remedy and employed therapeutically or preventively in a "safe" and "efficacious" manner according to the principle of symptom-based similitude, it should be subjected to testing in human beings to investigate its "primary effects', 'pathogenetic symptoms' or 'adverse effects'. In this way, any animal product might be used homeopathically, provided those premises are observed. This is, indeed, the case of many nosodes (Medhorrinum, Psorinum, Tuberculinum, etc.), which were subjected to pathogenetic testing and are used in compliance with the homeopathic requisite of symptomatic individualization.

Contrariwise, according to Hahnemann, the use of nosodes selected based on the "principle of etiological identity' (isopathy), i.e., the administration of 'the product of infectious agents to treat (or prevent) diseases 
caused by the identical etiologic agent', is not supported by the homeopathic epistemological model. Properly named "isoprophylaxis" or "isopathic immunization" (instead of "homeoprophylaxis" or "homeopathic immunization"), this approach is suggested by Golden and followers as a prophylactic procedure applicable to all epidemic diseases of childhood. Consistently, they suggest replacing the conventional schedule by an isoprophylactic program (Table 1), which according to them is "comparably effective to conventional vaccines, and is non-toxic" [29].

Table 1. Homeopathic preventative program against infectious diseases

\begin{tabular}{|c|c|c|}
\hline Recommended age & Remedy & Potency \\
\hline 1 month & Pertussin & 200 \\
\hline 2 months & Pertussin & $200,200,200$ \\
\hline 3 months & Pneumococcinum & 200 \\
\hline 4 months & Pneumococcinum & $200,200,200$ \\
\hline 5 months & Lathyrus sativus & 200 \\
\hline 6 months & Lathyrus sativus & $200,200,200$ \\
\hline 7 months & Haemophilis & 200 \\
\hline 8 months & Haemophilis & $200,200,200$ \\
\hline 9 months & Meningococcinum & 200 \\
\hline 10 months & Meningococcinum & $200,200,200$ \\
\hline 11 months & Tetanus Toxin & 200 \\
\hline 12 months & Tetanus Toxin & $200,200,200$ \\
\hline 14 months & Pertussin & 10M, 10M, 10M \\
\hline 16 months & Pneumococcinum & 10M, 10M, 10M \\
\hline 18 months & Lathyrus sativus & 10M, 10M, 10M \\
\hline 20 months & Haemophilis & 10M, 10M, 10M \\
\hline 22 months & Meningococcinum & 10M, 10M, 10M \\
\hline 24 months & Tetanus Toxin & 10M, 10M, 10M \\
\hline 26 months & Pertussin & 10M, 10M, 10M \\
\hline 30 months & Pneumococcinum & 10M, 10M, 10M \\
\hline 36 months & Lathyrus sativus & $10 \mathrm{M}, 10 \mathrm{M}, 10 \mathrm{M}$ \\
\hline 40 months & Haemophilis & $10 \mathrm{M}, 10 \mathrm{M}, 10 \mathrm{M}$ \\
\hline 44 months & Meningococcinum & $10 \mathrm{M}, 10 \mathrm{M}, 10 \mathrm{M}$ \\
\hline 48 months & Tetanus Toxin & $10 \mathrm{M}, 10 \mathrm{M}, 10 \mathrm{M}$ \\
\hline 52 months & Pertussin & $10 \mathrm{M}, 10 \mathrm{M}, 10 \mathrm{M}$ \\
\hline
\end{tabular}




\begin{tabular}{|l|l|l|}
\hline 58 months & Pneumococcinum & $10 \mathrm{M}, 10 \mathrm{M}, 10 \mathrm{M}$ \\
\hline \hline 64 months & Lathyrus sativus & $10 \mathrm{M}, 10 \mathrm{M}, 10 \mathrm{M}$ \\
\hline \hline 70 months & Haemophilis & $10 \mathrm{M}, 10 \mathrm{M}, 10 \mathrm{M}$ \\
\hline \hline 76 months & Meningococcinum & $10 \mathrm{M}, 10 \mathrm{M}, 10 \mathrm{M}$ \\
\hline \hline 84 months & Tetanus Toxin & $10 \mathrm{M}, 10 \mathrm{M}, 10 \mathrm{M}$ \\
\hline
\end{tabular}

Upon subjecting my remarks to criticism, and seeking to substantiate the use of nosodes prepared from infectious agents as a standard prophylactic practice [2], Golden made several mistakes and incurred in contradictions, as he also did in debates with other advocates of the homeopathic epistemological model [30, $31]$.

To begin with, although Hahnemann clearly defined "isopathy" (isotherapy) as "a method of curing a given disease by the same contagious principle that produces it" based on the "principle of etiological identity" (aequalia aequalibus curentur), Golden argues that his "preventive program" [29] is not isopathy, but is based on the "principle of similars", for which purpose he adduces the following misconceptions:

- An isopathic remedy is made from a patient's own materials (as a fact, this is an autoisopathic remedy, while the remedies prepared from other people's materials are isopathic);

- Isopathic remedies are made of "strains" or "subtypes" of microorganisms that are probably not "identical" to the one causing a given epidemic (as a fact, no matter whether they are identical or "probably" non-identical, they are prescribed based on the principle of etiological identity, instead of the principle of symptom-based similarity);

- Nosodes are as used "preventive" rather than as "curative" means, thus complying with Hahnemann's prohibition (as a fact, either indication is based on one and the same principle of etiological identity, while homeopathy applies the principle of symptom-based similarity to the cure and prevention of diseases);

- The process of "potentization" turns an "isotherapic" remedy into a "simillimum" (this notion was advocated by Hering and Stapf, however, without any foundation in the homeopathic doctrine, according to which the simillimum is the ideal homeopathic remedy).

Golden states, "Teixeira failed to fully understand the principle of similars", to then have recourse to flimsy arguments to characterize his isopathic practice as a legitimate homeopathic approach. Those misguided endeavors notwithstanding, Golden grounds his preventive approach on the "principle of etiological identity" and fully dismisses the "symptom-based similarity" that characterizes the homeopathic "principle of similars".

\section{Evidences on the safety of homeoprophylaxis and isoprophylaxis}

According to Hahnemann, the use of 'dynamized remedies' in compliance with the assumption of 'individualization of a single remedy' is the single (safe and effective) application of the homeopathic method of treatment (and prevention), because the "totality of the symptoms" reflects "the affection of the vital force", and "must be the principal, or the sole means, whereby the disease can make known what remedy it requires" (Organon of Medicine, § 7). Therefore, in addition to the 'constitutional' homeopathic treatment, which aims at minimizing the individual susceptibility that predisposes to disease, the use of 'remedies of the epidemic 
genius' as homeopathic therapeutic (or prophylactic) means is the safest and most effective way to perform specific homeoprophylaxis.

Although Golden does not choose potentized remedies based on the individualizing totality of symptoms, which is the sine qua non condition for "safe" and "efficacious" application of the "principle of symptom-based similarity", the remedies he selected for his preventive program (Lathyrus sativus, Pneumococcinum, Tetanus toxin, and others) were, indeed, subjected to homeopathic trials in humans, when they showed a wide variety of 'pathogenetic effects' that are liable to cause 'adverse effects' in susceptible children when prescribed with disregard for the three fundamental homeopathic premises. By stating that his program "offers a comparable level of protection against targeted infectious diseases to vaccines, without any accompanying risk of toxic damage" [30], Golden ignores the major premise underlying the principle of symptom-based similarity: "medicines can show nothing curative besides their tendency to produce morbid symptoms in healthy persons and to remove them in diseased persons" (Organon of Medicine, § 22). The reason is that any substance might only heal symptoms if it is able to induce them, and thus cannot exhibit an "efficacy" (protection) comparable to the ones of vaccines "without any accompanying risk of toxic damage". In other words, if a substance is inherently able to elicit morbid symptoms, it is not exempt from causing toxic/adverse effects.

In regard to the safety of his "preventative program" [29], Golden observes that the rate of adverse effects per individual is $9.2 \%$ (215 reactions/ 2,342 individuals) and the rate of adverse effects per dose $1.5 \%$, being the reactions typically "mild and brief". In premarket studies (phase II clinical trials) rigorously controlled to ensure the validity and reproducibility of the results (unlike the alleged findings reported by Golden), "common adverse reactions occur in $1 \%$ to less than $10 \%$ of vaccine doses" [32].

Contrary to Golden's estimates and illustrating the power of 'potentized substances' to cause pathogenetic symptoms (adverse events) when they are given to individuals with disregard for the homeopathic premise of 'symptom-based individualization' (nosodes, for example), the study "A systematic review of the quality of homeopathic pathogenetic trials (HTPs) published from 1945 to 1995" [33] showed that "156 HPTs on 143 medicines, involving 2,815 volunteers, produced 20,538 pathogenetic effects (median 6.5 per volunteer)" and called the attention to the high frequency of occurrence of "morbid symptoms" caused by potentized substances, "on average about $84 \%$ of volunteers receiving active treatment developed symptoms".

Several examples of such 'iatrogenic events' ('pathogenetic symptoms' or 'morbid symptoms'), which might serve as a warning against the potential danger implicit in Golden's "preventative program", are described in the materia medica of nosodes, as e.g., in "an involuntary proving of the Diphtherinum", which was administered to a girl for preventive purposes [34]. Based on the homeopathic epistemological model, one might predict that the same might be the case with other nosodes or any other homeopathic remedy not prescribed as a function of 'symptom-based individualization', their pathogenetic symptoms and the patient's individual pattern of susceptibility (idiosyncrasy).

"A girl nine years of age having been exposed, Nov. 13, to malignant diphtheria received Diphtherinum 1M (Skinner) three times daily for eleven days, as a prophylactic, developing chilliness, high temperature, red face. She complained of being tired and cold, severe pain on swallowing and on the 12th day the tonsils and posterior walls of the pharynx were covered with dirty gray, yellowish membrane, corrugated vertically, like the surface of a wash-board turned up. Thursday, Nov. 14, 1907, began powders, three each day for eight days, then two daily for two days. Nov. 23, complained of being tired, sat down to rest three times. Nov. 24, would lie down because tired, but after a while felt playful. Nov. 25, temperature 103, pulse 148, full, with throbbing of carotids, eyes bright, face flushed, with center of cheeks almost purple. Throat dark red, no membrane; but on posterior wall of throat, yellow, dirty cream color with dry membrane in folds, up and down. Monday night talks in sleep, with eyes wide open. Wanted imaginary objects taken from room, and to "make those people get away." Sat up and picked among bed-clothes for strap for her school books. Nov. 26, 
temperature 101.2, pulse 116, membrane lighter and moist, thin in middle of throat. Nov. 27, temperature 99.2, pulse 100. Throat clearing from middle. Jerking of single limb, or shoulder, or finger. Nov. 28, temperature 101.2, pulse 116. Desired to have mother hold her hand. Tongue whitish, with exceedingly red tip (moist). Nov. 29, temperature 101.2, pulse 116, breath offensive. Nov. 30, temperature 99.4, pulse 100. Membrane white, and showing more to front. Clearing from center of posterior wall of throat. Tongue coated whitish, with red papillae; very red tip, with a dark red spot in center of red tip. Slept well last night, until 4 A. M., then was restless and wakeful; moved and changed position, moved arms and legs often, snored and fan-like motion of ala nasi. Skin seemed dry, forehead moist along edge of hair, when first falling asleep." (The materia medica of the nosodes with provings of the x-ray, "Diphtherinum: an involuntary proving") [34]

Any discussion of the accuracy of Golden's findings demands proper analysis of the presence of "systematic error" or "bias" in the methods he employed [29], which even without such analysis are patently poor, as they exhibit many flaws relative to clinical epidemiology criteria, and the conclusions are inferred from insufficient data. For those reasons, Golden's results are scientifically questionable relative to both main requirements, to wit, "safety" (underestimation of adverse events) and "efficacy" (overestimation of effectiveness).

"A more detailed summary of my findings is shown in Table 2. The data is based on questionnaire responses from parents whose children used my HP program. Each response covered one year of a child's life. Some parents returned questionnaires over 6 years, and some only for the first year of the program. Fifteen data groups were divided into three groups of five, based on slight differences in the HP programs used. The third group (Series 11-15) was studied in greater detail in order to validate the findings of the earlier Series. Seven different tests were performed on Series 11-15 data." [29]

According to The Cochrane Collaboration [35], "a bias is a systematic error, or deviation from the truth, in results or inferences. Biases can operate in either direction: different biases can lead to underestimation or overestimation of the true intervention effect. Biases can vary in magnitude: some are small (and trivial compared with the observed effect) and some are substantial (so that an apparent finding may be entirely due to bias). Even a particular source of bias may vary in direction: bias due to a particular design flaw (e.g. lack of allocation concealment) may lead to underestimation of an effect in one study but overestimation in another study. It is usually impossible to know to what extent biases have affected the results of a particular study, although there is good empirical evidence that particular flaws in the design, conduct and analysis of randomized clinical trials lead to bias. Because the results of a study may in fact be unbiased despite a methodological flaw, it is more appropriate to consider risk of bias".

Bias is classified as: selection bias (random sequence generation or allocation concealment), performance bias (blinding of participants and personnel assessments should be made for each main outcome), detection bias (blinding of outcome assessment should be made for each main outcome), attrition bias (incomplete data of outcome assessment should be made for each main outcome) and reporting bias (selective reporting) among other types.

As a result of the methodological flaws in the design and conduction of his study on community-based prophylactic intervention (lack of sample randomization, blinding, effective control group and independent examiners) [29], Golden is guilty of various types of bias that might cause "deviation from the truth in his results or inferences", to wit: selection bias (biased allocation to interventions due to inadequate generation of a randomized sequence: lack of effective control group; non-random sampling; volunteer patients); performance bias (due to knowledge of the allocated interventions by participants and personnel during the study: lack of blinding); detection bias (due to knowledge of the allocated interventions by outcome assessors: lack of blinding of outcome assessors); attrition bias (due to amount, nature or handling of incomplete outcome data: incomplete response to long-term questionnaires, loss of participants); reporting bias (due to selective outcome reporting: use of incomplete questionnaires, analysis of partial groups). The absence of an 
effective control group, that ensures for the normality of the variances of the groups subjected to analysis, makes appropriate evaluation of the safety and intervention effectiveness impossible (due to the difficulty to assess individuals exposed to preventable diseases, for example), because comparison with national disease attack rates does not provide an "effective" control group (Golden's sample is of patients, which does not correspond to the national distribution, for example). Other confounding factors are the fact that $12 \%$ of the participants had been previously vaccinated and the positive expectations of the patients' parents (placebo effect), among others.

A posteriori, hoping to minimize those structural methodological flaws, Golden applied biased "tests to validate the measures", which being strongly criticized by the scientific community makes difficult to admit the findings reported in "Evidence of the Safety of HP Using Nosodes", "which clearly show that the use of appropriate long-term HP is significantly less damaging than vaccination, and in fact appears to be no less safe than the use of general or constitutional treatment as an immunisation option" [2, 29]. The same misgivings derived from the poor methodological quality of Golden's research hinder one from admitting the findings reported in "Scientific Evidence of the Effectiveness of HP using Nosodes", according to which it "offers a comparable level of protection against targeted infectious diseases to vaccines" [2,29]. The fact that such results were not published in a peer-reviewed scientific journal, where methods and data are systematically subjected to evaluation, endorse the present criticism.

Also other reviews pointed to the low methodological quality of the research conducted on isoprophylaxis, while stressing that well-designed scientific studies should be performed before it might be recommended as a safe and effective alternative to the conventional immunization of children: "substituting isopathic nosodes for vaccination in the hollow promise of safety and the hope for efficacy is simply bad medicine" [36].

"Over the past 100 years, Allopathic medicine has developed vaccines for nearly all serious epidemic diseases, and development of newer vaccines for less severe diseases continues at a feverish pitch. In keeping with the desire to prevent serious infectious disease and out of concern for the side effects of vaccination, some Homeopaths have developed a parallel system of homeoprophylaxis using remedies that are either nosodes of the specific disease, or remedies that have been highly effective in treating that disease. [...] Much of the evidence for safety and efficacy of homeoprophylaxis is anecdotal. Dr. Grimmer reported that over 30,000 individuals received Lathyrus sativa to prevent Polio and no one had a side effect to his knowledge. Isaac Golden reports that out of over 1300 children who received generalized homeoprophylaxis for multiple diseases, approximately $10 \%$ had side effects although the majority was very mild and brief. His results are from a survey in which only $70 \%$ of the population responded. [...] Although unlikely, generalized Homeoprophylaxis may someday be a valuable tool for the practitioner. Before that day will be possible, standardized, Allopathic style prospective testing must be performed. Safety analysis that is reliable must be obtained. Research in this area should be supported because of the suggestion of efficacy present in the data so far. Generalized substitution as a safe alternative to Allopathic vaccination should be avoided, unless the practitioner is prepared to clarify the experimental nature and potential risks of this approach. Our patients are faced with difficult decisions regarding vaccinations. Many homeopaths have appropriately voiced concerns with the vaccination process. But substituting isopathic nosodes for vaccination in the hollow promise of safety and the hope for efficacy is simply bad medicine. [...]" [36]

\section{Evidences on the effectiveness of homeoprophylaxis and isoprophylaxis}

In his response article [2], Golden states that I "used a double standard when comparing evidence using GE remedies and nosodes" and "appeared to be unaware of scientific evidence which is available supporting the prophylactic use of nosodes". In my prior review [1], I did not used "a double standard when comparing evidence using GE remedies and nosodes", but reported the lack of reliable evidence in support of either approach. 
"After defining the individualized medicine (epidemic genius) for the different stages of a given epidemic, according to the state of the art of homeopathic semiology as laid out by Hahnemann, large-scale application in prevention and treatment must be followed up through experimental and observational studies properly designed, to enable results to be analyzed complying with the tenets of modern clinical epidemiology and to avoid both systematic errors (biases) and chance effects that contaminate isolated results. In spite of the centuries-old evidences described in this paper, most attempts in this area only exhibit as results reports of "series of treated cases", with a low level of scientific significance, making thus impossible to infer definitive conclusions. Among attempts carried out in Brazil, only Marino in his MA dissertation assessing the action of single and individualized Eupatorium perfoliatum in the prevention of dengue during the 2001 epidemic in São José do Rio Preto, SP, included a control group and statistical analysis, showing a fall in the incidence of the disease after the homeopathic intervention. These same methodological criteria ought to be reproduced in the design of research projects employing dynamized isoprophylaxis, as mentioned above widely publicized as preventive against epidemic diseases, but without any support in Hahnemann's homeopathic epistemology and showing no scientific evidence regarding the benefit and risks of such method." ([1], page 166)

Those remarks notwithstanding, it should be admitted that the studies that used individualized remedies (symptom-based GE) for the treatment and prevention of epidemic diseases (homeoprophylaxis) are much more consistent, exhibit better methodological design and scientific documentation than the ones that performed isoprophylaxis, from the careful reports of Hahnemann of series of cases and prevention (scarlet fever, typhus, remittent fevers, cholera) $[21-23,25,26,37]$ to the more recent therapeutic and preventive protocols (influenza, cholera, dengue) [38-45].

Among the more recent studies, the multicenter protocol for randomized controlled trials (RCT) formulated by Dantas et al. [46] stands out, as it is rigorously based on the homeopathic epistemological premises, as well as on ethical and scientific fundamental assumptions and prescribes a "rigorous methodological design". Initially formulated for the treatment of an epidemic disease (influenza) and indicating the use of individualized GE remedies, it might be easily adapted to homeoprophylaxis, by "employing the same remedies that presented similarity with the totality of characteristic symptoms of the initial stage of epidemics", and to isoprophylaxis, i.e., when "nosodes" are used (provided that the same "rigorous methodological design" is complied with).

The same rigorous methodological design is currently being used by a group of researchers in the elaboration of a multicenter RCT assessing the effectiveness and efficacy of individualized GE remedies for the prevention and treatment of dengue fever involving various Brazilian states and counties exhibiting high incidence and prevalence rates of infection ("Protocol for prevention and treatment of dengue fever and its complications") [47], thus seeking to add improved data to the ones provided by previous non-controlled protocols or using non-individualized remedies. Incidentally, I would like to suggest those investigators to assess the possible different stages and forms of disease to select more accurate 'preventive' and 'therapeutic' remedies, as Hahnemann did.

Rather than criticizing my suggestions [1] to improve the data provided by previous studies, which exhibited low methodological quality, by means of "experimental and observational studies properly designed" ("the use of RCTs is increasingly seen within the allopathic literature to be problematical due to fundamental flaws in design which means that the practical relevance of findings is frequently compromised" [2]), Golden should make profit of the above mentioned examples of rigorous methodological designs to improve the scientific quality of the studies assessing isoprophylaxis, most of which report insufficient data and exhibit significant methodological flaws [48]. Although some models of observational studies are fit to demonstrate the plausibility of homeopathy, experimental studies as the RCTs can and should be adapted to the homeopathic model to thus minimize the occurrence of systematic error (placebo effect) [49] that might confound the results. 
In an example of "well-designed" cohort study, Bracho et al. [50] performed a very large-scale isoprophylaxis intervention against leptospirosis in Cuba. The nosode was prepared from four inactivated Leptospira circulating strains (200c and 10M) and was administered to 2.3 million persons at high risk in an epidemic in a region affected by natural disasters. The data from surveillance were used to measure the impact of the intervention by comparing with historical trends and non-intervention regions. A significant decrease of the disease incidence was observed in the intervention regions (below of the historic median), and no such modifications were observed in non-intervention regions. The number of cases of leptospirosis dropped from $38 \mathrm{cases} /$ week per 100,000 individuals at the beginning of the study to 3-4 cases/week per 100,000 within three weeks. Although lack of randomization and use of conventional prophylactic measures (vaccination and chemoprophylaxis) in only $3 \%$ of the population were cited as possible biases, the promising results obtained in such a large sample minimize that suspicion [48]. However, further studies including RCTs with smaller samples might provide further evidences to support stronger conclusions.

In this and other similar epidemics in which the available therapeutic and/or prophylactic measures are insufficient or non-existent, isoprophylaxis might be experimentally used as an attempt to minimize the harms to the population without any major implications. However, until there is reliable scientific evidence to indicate it as a safe and effective alternative to the classical 'immunization schedule' for child diseases, which effectively protects children from severe and fatal diseases, indiscriminate use of 'isopathic immunization' should be discouraged on the grounds that it transgresses bioethical norms [1].

\section{Ethical problems of replacing 'classical immunization' by 'isopathic immunization'}

Based on the homeopathic epistemological premises and above mentioned evidences, in my previous review [1] I criticized the indiscriminate use of non-individualized homeoprophylaxis and isoprophylaxis unsupported by scientific evidences attesting to their safety and effectiveness. In addition, I stated that such practice "transgress[es] the bioethical principles of beneficence and non-maleficence", which was disappointing to "many thousands of homoeopathic practitioners internationally who use appropriate HP programs based on nosodes", according to Golden [2]. In addition to the ethical implications involved, any excess committed 'in the name of the homeopathy' might damage to its reputation, as I discuss below.

"Unfortunately, during the last years a series of proposals were made in Brazil for the prophylaxis and/or treatment of dengue and influenza epidemics that do not comply with Hahnemann's homeopathic epistemology, but indicate the use of homeopathic complexes (associations of homeopathic and/or isopathic medicines with disregard of previous pathogenetic experimentation as well as individualization according to the characteristic symptomatic totality of each stage of an ongoing epidemic) on the whole population of a given area without using structured research protocols able to assess the efficacy and safety of such practices. The indiscriminate distribution of homeopathic medicines promising to immunize populations against a given epidemic without data on their efficacy and possible side effects represents a risk to public health as may lead populations to ignore hygienic and prophylactic measures proved effective by feeling 'protected' by homeopathy. In the case of dynamized isoprophylaxis, which dismisses pathogenetic experimentation and the principle of similitude - main pillars of rational homeopathic practice - the problem is even more acute: by irresponsibly suggesting to replace official vaccination schemes with 'schemes of isopathic vaccinations' with no scientific evidence whatsoever of efficacy and safety, proposers of this idea transgress the bioethical principles of beneficence and non-maleficence." ([1], pages 166-167)

In regard to the use of 'isopathic immunisation programs' in Australia, instead conventional immunization, the National Centre for Immunisation Research \& Surveillance published a factsheet entitled "Homoeopathy and vaccination" [51], in which it addresses the ethical aspects of that approach in view of the lack of scientific evidences to support it. The Australian Register of Homoeopaths (AROH) published a "Statement on the use of homoeopathic medicines for prophylaxis" [52], which is a strict protocol that must be followed by all 
"homeopathy practitioners" that prescribe isopathic immunization (HP), "after the client has discussed immunisation with a medical practitioner, and made a carefully considered decision not to use immunisation".

"[...] Unlike conventional vaccines, homoeopathic preparations use nosodes which are diluted to such an extent that no trace of the original pathogen (nosode) remains. These preparations are given orally to babies on a regular basis (usually monthly to bimonthly) from 1 month to 26 months of age and cost around $\$ 95$, plus postage and handling, for the completed schedule. [...] Therefore, unlike conventional immunisation, there is no rigorously tested research evidence to support this form of therapy in the prevention of childhood infectious diseases. Some people believe that homoeopathic preparations will provide protection against infectious diseases on the basis of very little evidence. For example, Golden's unpublished survey of 150 children who had received homoeopathic immunisation 5-10 years prior to his study demonstrated that $72 \%-100 \%$ of children did not develop the disease against which they had been treated with homoeopathic preparations. However, 20\%-30\% of these children had also received conventional immunisation. These findings are not surprising because conventional immunisation programs have eradicated or radically reduced the occurrence of most childhood infectious diseases in our country. Therefore, the incidence of these infections is so low that you would not expect to see it in a sample as small as 150 children, whether or not they had received homoeopathy. Interestingly, 15 children in Golden's study stated they had experienced side effects to the homoeopathic 'vaccines'. [...] The Australian Register of Homoeopaths (AROH) states homoeopathics 'should not be recommended as a substitute for (conventional) immunisation'. Unless reliable scientific research is conducted which demonstrates the effectiveness and safety of homoeopathic preparations in preventing infectious diseases, they cannot be recommended as an alternative to conventional immunisation [...].” [51]

“[...] C. Where the efficacy and/or effectiveness of HP has not been well demonstrated to be as high as that achieved with available immunisation for a specific disease considering any relevant factors (e.g. comparability and reliability of data sets, relevance of the conditions surrounding the data collection to those relating to the patient in question), HP should not be recommended as a substitute for immunisation, and should only be considered by the practitioner after the client has discussed immunisation with a medical practitioner, and made a carefully considered decision not to use immunisation. Any practitioners recommending HP should be prepared to support such recommendation with data (in a Court if necessary). However, a patient (after examination of the relevant information), considering risks and benefits may choose to use HP after deciding against an available immunisation, or for a disease where an immunisation is not available, and/or as part of an ethical clinical trial. In certain circumstances, however, such decisions have lead parents into legal proceedings [...]". [52]

In line with the Department of Health's advice, the British Homeopathic Association recommends that immunization should be carried out in the normal way using the conventional tested and approved vaccines. In a factsheet entitled "Homeopathy and immunisation" [53], 'isopathic immunization' is criticized together with the warning that "relying on nosodes instead of immunisation may create a false sense of security, since efficacy is not proven", as I had observed [1]. Analogously, the Royal London Hospital for Integrated Medicine does not recommend or prescribe homeopathic remedies to replace the Department of Health's childhood immunization program [54].

"[...] There are no proven homeopathic substitutes for immunisation. Some people have suggested using 'nosodes' (homeopathic preparations of the 'bugs' which cause the diseases). There is currently no evidence that nosodes are effective in humans. Relying on nosodes instead of immunisation may create a false sense of security, since efficacy is not proven. [...] Homeopathic medicines prescribed by trained practitioners can successfully treat epidemics of infectious disease, even where there are no other alternatives. For example, homeopathic medicines have been shown to relieve and shorten the duration of symptoms during outbreaks of influenza. [...] You may be prescribed a homeopathic medicine which has been individually selected for you. 
This medicine may boost your overall wellbeing and health, making it less likely that you will catch an infection or help you to recover more quickly should you become ill. This is known as a constitutional prescription. [...] The Faculty of Homeopathy follows the Department of Health guidelines on immunisation and recommends that immunisation be carried out in the normal way unless there are medical contraindications." [53]

In the USA, the National Center for Complementary and Alternative Medicine (NCCAM) also manifested to be against 'isopathic immunization', but recommends classical immunization: "Certain homeopathic products (called 'nosodes' or 'homeopathic immunizations') have been promoted by some as substitutes for conventional immunizations, but data to support such claims is lacking. The National Center for Complementary and Alternative Medicine (NCCAM) supports the Centers for Disease Control and Prevention's recommendations for immunizations/ vaccinations" [55]. Calling the attention to the fact that "there has been a resurgence of certain vaccine-preventable diseases in the United States in recent years" and "that children who received care from complementary health practitioners were substantially less likely to get recommended immunizations and were more likely to be diagnosed with a vaccine-preventable disease", the NCCAM tells its members that "it is essential that we recognize the extraordinary success of childhood vaccination, and that we look to the abundant scientific evidence that documents the safety and vital role of vaccines in the health of our Nation" [56].

The position adopted by the Brazilian Homeopathic Medical Association (AMHB) even for the accreditation of specialists in homeopathy, is to comply with the orientations formulated in the "National Program of Immunizations", and warns its members that systematic avoidance of vaccines for the prevention of childhood diseases "leaving them vulnerable to certain diseases against which they could be protected through vaccination" is a blatant transgression of the "Brazilian Code of Medical Ethics" (article 32: "It is forbidden to the physician not to use all available means of diagnosis and treatment at his or her hands for the benefit of the patient"). In addition, by not allowing their patients to be vaccinated, or even advertising against vaccination, doctors not only create a problem for health authorities, but also transgress Decree 12,342, from September 27 1978, which establishes vaccination as mandatory in Brazil (article 14: "The doctor should strive to improve the overall health conditions and the standards of the medical services, as well as assume their share of responsibility in regard to public health, health education and health legislation"; article 21: "It is forbidden to the doctor not to cooperate with the health authorities or contravene the relevant legislation"). According to the above mentioned Decree, when a doctor considers that a given vaccine might be harmful for a patient on an individual basis, he or she might contraindicate it, and assume the responsibility for that decision [57].

Therefore, by replacing effective (safe) official immunization programs by isopathic immunization unsupported by scientific evidences, homeopathic doctors "transgress the bioethical principles of beneficence and non-maleficence", as they no longer employ "all available means of diagnosis and treatment in their hands for the benefit of the patient", might cause undesirable adverse events and impair their country public health conditions by allowing diseases that are controlled or eradicated by classic immunization to affect the population. In addition, when "advertising against vaccination", homeopaths promote criticism against homeopathy, which is unjustified, as homeopathy does not endorse such recommendation. This posture soils the image of homeopathy, and contributes to undermine its global acceptance and dissemination. It is worth to observe that some studies showed that homeopathic "doctors" recommend classical vaccination more frequently than the lay homeopathic "practitioners" [58-63].

"Childhood Vaccinations - Vital to Our Children's Health. People turn to complementary and alternative medicine (CAM) seeking better health. Several studies have found an association between use of CAM and positive health behaviors such as getting regular exercise, not using tobacco products, and following 
a healthy diet. CAM use also has been associated with higher rates of vaccination for influenza, pneumococcus, and hepatitis B among adults. Unfortunately, however, this may not be the case for vaccinations in children. A recently reported NCCAM-funded study in the Maternal and Child Health Journal showed that children in Washington State who received care from CAM providers were substantially less likely to get recommended immunizations and were more likely to be diagnosed with a vaccine-preventable disease. The investigators note that their findings do not provide an explanation for the association. For example, it is possible that the study's results reflect an increased tendency of parents who are already vaccine-hesitant to seek out CAM professionals, a direct influence of CAM providers on parents' attitudes, or another explanation. Nonetheless, as a physician and Director of NCCAM, I find these results troubling in and of themselves. It is very difficult for most Americans to remember that polio and diphtheria regularly killed or permanently injured thousands of people in the United States yearly, as recently as the last century. In fact, polio has been eradicated in the United States and diphtheria is very rare because of vaccinations. However, these diseases have not yet been eliminated worldwide and could easily return to the United States. The Washington State study is especially troubling in light of reports from the Centers for Disease Control and Prevention (CDC) that there has been a resurgence of certain vaccine-preventable diseases in the United States in recent years. For example, in 2010, 8,627 cases of whooping cough (pertussis) including 10 infant deaths were reported throughout California - the largest number of cases reported in 63years. The benefits of vaccination in preventing illness and death have been repeatedly proven and greatly outweigh the risks. I fully support the CDC's current evidence-based recommendations for pediatric vaccinations, and I urge parents to safeguard their children by following these recommendations. I also urge all health care provider organizations - including CAM organizations - to raise vaccine awareness among their members, and enlist them in efforts to help increase adherence to childhood vaccinations. It is essential that we recognize the extraordinary success of childhood vaccination, and that we look to the abundant scientific evidence that documents the safety and vital role of vaccines in the health of our Nation." (Josephine P. Briggs, Director of the NCCAM) [63]

\section{Conclusions}

The homeopathic model of treatment (and prevention) applies the principle of symptom-based similitude to prescribe individualized remedies that were shown to induce similar symptoms in pathogenetic trials. In this regard, any type of substances (from the mineral, plant or animal kingdom, either natural or synthetic) might be used in a homeopathic manner, in ponderable or infinitesimal doses. For that reason, also modern drugs might be used in agreement with the principle of symptom-based similitude, thus representing an addition of thousands of new remedies to the homeopathic materia medica [64-67].

By the same token, any treatment that merely uses 'potentized remedies' with disregard for the homeopathic epistemological premises cannot be considered as "homeopathic". This is the case, e.g., of isoprophylaxis, which uses nosodes based on the principle of etiological identity, with full neglect of the similarity of symptoms, pathogenetic studies and individualization of treatment.

By applying those same basic assumptions to the prevention of epidemic diseases (homeoprophylaxis), remedies similar to the epidemic genius of the initial stage of an epidemic outbreak might be used in a homeopathically prophylactic manner to prevent transmission to susceptible individuals. Although all outbreaks of a same epidemic disease are caused by the same microorganism (etiological agent), the symptoms of each individual outbreak should be surveyed anew in order to select an individualized remedy for each particular stage.

Although most homeopathic studies targeting the prophylaxis of epidemics used methods unfit to give accurate answers to the questions on the efficacy and safety of homeoprophylaxis and isoprophylaxis, novel models of experimental and observational studies are emerging, the results of which might provide (or not) 
the evidences required vis-à-vis the current medical mainstream. The example provided by those studies should be followed by homeopathic practitioners devoted to the propagation of homeo- and isoprophylaxis for the sake of their patients' wellbeing and the health of the community at large. In this regard, is worth to bear in mind that the global consensus of homeopathic institutions worldwide states that "unless reliable scientific research is conducted which demonstrates the effectiveness and safety of 'homoeopathic' preparations in preventing infectious diseases, they cannot be recommended as an alternative to conventional immunization".

In spite of the enormous benefits that conventional immunization programs afford in the public health sphere, adverse reactions and aggravation of chronic diseases might be found, when their effects are evaluated based on patterns of individual susceptibility. Based on well-justified clinical and scientific reasons [68, 69], homeopathic doctors are entitled to contraindicate any vaccine to avoid further impairment of the patient's health.

The same criticism I directed in other article [70] to homeopathic practice unsupported by sound epistemological and scientific criteria (non-individualized medication, use of complexes, systematic discontinuance of conventional medication for no clear reason, etc.) also applies to isoprophylaxis:

"Homeopathy is a serious thing! Cannot be regarded as a dazzle of 'alternative' doctors who despise the integrity of their patients because they believe in an 'absolute and immediate power' of any prescribed homeopathic substance, disregarding, in most cases, the criterion of drug individualization, fundamental for the success of the homeopathic treatment." [70]

\section{References}

[1] Teixeira MZ. Homeopathy: a preventive approach to medicine? Int J High Dilution Res. 2009; 8(29): 155172. Available at: http://www.feg.unesp.br/ ojs/index.php/ijhdr/article/viewFile/360/407.

[2] Golden I. The Philosophical and Evidentiary Basis of Homoeopathic Immunisation: a Response to Teixeira. Int J High Dilution Res [online]. 2014; 13(46): 45-53. Available from: http://www.feg.unesp.br/ ojs/index.php/ijhdr/article/view/687/692

[3] Hahnemann S. Organon of medicine. 6th Edn. (Translated by William Boericke). New Delhi: B Jain Publishers, 1991.

[4] Dudgeon RE. The lesser writings of Samuel Hahnemann. New Delhi: B. Jain Publishers; 1995 (Reprint edition).

[5] Teixeira MZ. Scientific evidence of the homeopathic epistemological model. Int J High Dilution Res. 2009; 10(34): 46-64. Available at: http://www.feg.unesp.br/ ojs/index.php/ijhdr/article/viewFile/421/459.

[6] Teixeira MZ. Semelhante cura semelhante: o princípio de cura homeopático fundamentado pela racionalidade médica e científica [Similar cures similar: the homeopathic principle of cure as grounded on medical and scientific reason]. São Paulo: Editorial Petrus, 1998.

[7] Teixeira MZ. Similitude in modern pharmacology. Homeopathy. 1999; 88(3): 112-120.

[8] Teixeira MZ. Evidence of the principle of similitude in modern fatal iatrogenic events. Homeopathy. 2006; 95(4): 229-236. 
[9] Teixeira MZ. NSAIDs, Myocardial infarction, rebound effect and similitude. Homeopathy. 2007; 96(1): 67 68.

[10] Teixeira MZ. Bronchodilators, fatal asthma, rebound effect and similitude. Homeopathy. 2007; 96(2): 135 137.

[11] Teixeira MZ. Antidepressants, suicidality and rebound effect: evidence of similitude? Homeopathy. 2009; 98(2): 114-121.

[12] Teixeira MZ. Statins withdrawal, vascular complications, rebound effect and similitude. Homeopathy. 2010; 99(4): 255-262.

[13] Teixeira MZ. Rebound acid hypersecretion after withdrawal of gastric acid suppressing drugs: new evidence of similitude. Homeopathy. 2011; 100(3): 148-156.

[14] Teixeira MZ. Rebound effect of drugs: fatal risk of conventional treatment and pharmacological basis of homeopathic treatment. Int J High Dilution Res. 2012; 11(39): 69-106.

[15] Teixeira MZ. Antiresorptive drugs (bisphosphonates), atypical fractures and rebound effect: new evidence of similitude. Homeopathy. 2012; 101(4): 231-242.

[16] Teixeira MZ. Immunomodulatory drugs (natalizumab), worsening of multiple sclerosis, rebound effect and similitude. Homeopathy. 2013; 102(3): 215-224.

[17] Teixeira MZ. Rebound effect of modern drugs: serious adverse event unknown by health professionals. Rev Assoc Med Bras. 2013; 59(6): 629-638.

[18] Posadzki P, Alotaibi A, Ernst E. Adverse effects of homeopathy: a systematic review of published case reports and case series. Int J ClinPract. 2012, 66(12): 1178-1188.

[19] Teixeira MZ. Plausibility of the implausible: is it possible that ultra-high dilutions 'without biological activity' cause adverse effects? Int J High Dilution Res. 2013; 12(43): 41-43.

[20] Hahnemann S. Essay on a new principle for ascertaining the curative power of drugs, with a few glances at those hitherto employed. In: Dudgeon RE (ed). The lesser writings of Samuel Hahnemann. New Delhi: B. Jain Publishers, 1995 [Reprint edition].

[21] Hahnemann S. Cure and prevention of scarlet-fever. In: Dudgeon RE (ed). The lesser writings of Samuel Hahnemann. New Delhi: B. Jain Publishers, 1995 [Reprint edition].

[22] Hahnemann S. On the power of small doses of medicine in general, and of Belladonna in particular. In: Dudgeon RE (ed). The lesser writings of Samuel Hahnemann. New Delhi: B. Jain Publishers, 1995 [Reprint edition].

[23] Hahnemann S. Treatment of the typhus or hospital fever at present prevailing. In: Dudgeon RE (ed). The of Samuel Hahnemann. New Delhi: B. Jain Publishers, 1995 [Reprint edition].

[24] Hahnemann S. How can small doses of such very attenuated medicines as homoeopathy employs have any action on the sick? In: Dudgeon RE (ed). The lesser writings of Samuel Hahnemann. New Delhi: B. Jain Publishers, 1995 [Reprint edition]. 
[25] Hahnemann S. Cause and prevention of the Asiatic cholera. In: Dudgeon RE (ed). The lesser writings of Samuel Hahnemann. New Delhi: B. Jain Publishers, 1995 [Reprint edition].

[26] Hahnemann S. Appeal to thinking philanthropists respecting the mode of propagation of the Asiatic cholera. In: Dudgeon RE (ed). The lesser writings of Samuel Hahnemann. New Delhi: B. Jain Publishers, 1995 [Reprint edition].

[27] Dudgeon RE. Hahnemann's discovery of the prophylactic powers of belladonna in scarlet fever Allopathic testimony to this prophylactic. In: Dudgeon RE (ed.). Lectures on the theory \& practice of homoeopathy. New Delhi: B Jain Publishers; 2002 (Reprint edition).

[28] Kent, JT. Lectures on homoeopathic philosophy. Berkeley: North Atlantic Books; 1979 (Reprint edition).

[29] Golden I. Homoeopathic preventative program against infectious diseases. In: The latest research into the effectiveness and safety of long-term homoeoprophylaxis. Homeopathy 4 Everyone, December 16, 2006. Available at: http://hpathy.com/scientific-research/the-latest-research-into-the-effectiveness-and-safety-ofhomeoprophylaxis/.

[30] Bathia M, Golden I. Dr Isaac Golden. Homeopathy 4 Everyone, December 15, 2006. Available at: http://hpathy.com/homeopathy-interviews/dr-isaac-golden-2/.

[31] Bathia M, Vithoulkas G. George Vithoulkas. Homeopathy 4 Everyone, April 15, 2007. Available at: http://hpathy.com/homeopathy-interviews/george-vithoulkas-3/.

[32] Public Health Agency of Canada. Canadian Immunisation Guide, Part 2, Vaccine Safety. Available at: http://www.phac-aspc.gc.ca/publicat/cig-gci/p02-01-eng.php.

[33] Dantas F, Fisher P, Walach H, Wieland F, Rastogi DP, Teixeira H, et al. A systematic review of the quality of homeopathic pathogenetic trials published from 1945 to 1995. Homeopathy. 2007; 96(1): 4-16.

[34] Allen HC. Diphtherinum: an involuntary proving. In: The materia medica of the nosodes with provings of the $\quad$-ray. Philadelphia: Boericke \& Tafel, 1910. Available at: http://www.homeoint.org/seror/nosodes/diphtherinum.htm.

[35] The Cochrane Collaboration. Cochrane Bias Methods Group. Assessing risk of bias in included studies. Available at: http://bmg.cochrane.org/assessing-risk-bias-included-studies.

[36] Hoover, TA. Homeopathic prophylaxis: fact or fiction. J Am Inst Homeopath. 2001; 94(3): 168-175. Available at: http://toddhoovermd.com/articles/epidemic-diseases-and-homeopathic-prophylaxis.html.

[37] Hahnemann S. Some kinds of continued and remittent fevers. In: Dudgeon RE (ed). The lesser writtings of Samuel Hahnemann. New Delhi: B. Jain Publishers, 1995 [Reprint edition].

[38] British Homoeopathic Society (Meeting). Discussion on the treatment of influenza and its complications as seen in the present epidemic. Br Homeopath J. 1918; 8(12): 305-312. Available at: http://www.homeopathyforflu.com/bhj1918.htm.

[39] Baker WF. Research work in Gelsemium sempervirens and Bryonia alba in influenza. J Am Inst Homeopath. 1920; 12: 695-698. 
[40] Dewey WA. Homeopathy in influenza: a chorus of fifty in harmony. J Am Inst Homeopath. 1921; 11: 1038-1043. Available at: http://www.homeopathyforflu.com/dewey.htm.

[41] Leary B. Cholera 1854: update. Br Homeopath J. 1994; 83: 117-121.

[42] Leary B. The homeopathic management of cholera in the nineteenty century with special reference to the epidemic in London, 1854. Med Ges Gesch. 1997; 16: 125-144.

[43] Land ST. 20 years ago: The British Homoeopathic Journal, October 1987. Homeopathy. 2007; 96(4): 279 281.

[44] Marino R. Homeopathy and collective health: the case of dengue epidemics. Int J High Dilution Res. 2008; 7(25): 179-185. Available at: http://www.feg.unesp.br/ ojs/index.php/ijhdr/article/view/312/373.

[45] Liga Medicorum Homoeophatica Internationalis. Epidemic diseases: LMHI guideline for clinical data collection. Available at: http://iga.iwmh.net/index.php?menuid=49\&reporeid=139.

[46] Dantas F, Mathie RT, Frye J, Nayak C. Homeopathy in the treatment of influenza: a data collection proposal. Int J High Dilution Res. 2008; 7(23): 56-62. Available at: http://www.feg.unesp.br/ ojs/index.php/ijhdr/article/view/284/352.

[47] Salles SAC, Novaes ARV, Perisse A, Prass-Santos C, Nunes L, Waisse S, Estrela WL. Protocol for prevention and treatment of dengue fever and its complications. Homeopathy. 2014; 103(1): 97. Available at: http://www.sciencedirect.com/science/article/pii/S1475491613001239.

[48] Roniger H, Jacobs J. Prophylaxis against Leptospirosis using a nosode: can this large cohort study serve as a model for future replications? Homeopathy. 2010; 99(3): 153-155.

[49] Teixeira MZ, Guedes CH, Barreto PV, Martins MA. The placebo effect and homeopathy. Homeopathy. 2010; 99(2): 119-129.

[50] Bracho G, Varela E, Fernandez R, Ordaz B, Marzoa N, Menéndez J, et al. Large-scale application of highly diluted bacteria for Leptospirosis epidemic control. Homeopathy. 2010; 99(3): 156-166.

[51] National Centre for Immunisation Research \& Surveillance. Homoeopathy and vaccination. NCIRS Fact sheet: December 2009. Available at: http://ncirs.edu.au/immunisation/fact-sheets/homeopathy-vaccinationfact-sheet.pdf.

[52] The Australian Register of Homoeopaths (AROH). AROH statement on the use of homoeopathic medicines for prophylaxis. Available at: http://www.aroh.com.au/Resources/Documents/AROH\%20HP\%20Statement\%204\%20Oct\%2013.pdf.

[53] British Homeopathic Association. Homeopathy and immunisation. Available at: http://www.britishhomeopathic.org/wp-content/uploads/2013/05/immunisation factsheet-2-1.pdf.

[54] Royal London Hospital for Integrated Medicine. FAQs/Policy Statements: Can I use complementary medicine instead of conventional immunisation? Available at: http://www.uclh.org/OurServices/OurHospitals/RLHIM/Pages/FAQ_RLHIM.aspx.

[55] National Center for Complementary and Alternative Medicine (NCCAM). Homeopathy: an Introduction (Side Effects and Risks). Available at: http://nccam.nih.gov/health/homeopathy\#hed6. 
[56] National Center for Complementary and Alternative Medicine (NCCAM). Vaccinations/ Immunisations for Children. Available at: http://nccam.nih.gov/health/vaccinations.

[57] Associação Médica Homeopática Brasileira (AMHB). Homeopatia e vacinas [Homeopathy and vaccines]. Available at: http://www.amhb.org.br/conteudo/317/0/homeopatia-e-vacinas.html.

[58] Sulfaro F, Fasher B, Burgess MA. Homoeopathic vaccination. What does it mean? Immunisation Interest Group of the Royal Alexandra Hospital for Children. Med J Aust. 1994; 161(5): 305-307.

[59] Ernst E, White AR. Homoeopathy and immunisation. Br J Gen Pract. 1995; 45(400): 629-630.

[60] Ernst E. Rise in popularity of complementary and alternative medicine: reasons and consequences for vaccination. Vaccine. 2001; 20 Suppl 1: S90-3.

[61] Lehrke P, Nuebling M, Hofmann F, Stoessel U. Attitudes of homoeopathic physicians towards vaccination. Vaccine. 2001; 19(32): 4859-4864.

[62] Downey L, Tyree PT, Huebner CE, Lafferty WE. Pediatric vaccination and vaccine-preventable disease acquisition: associations with care by complementary and alternative medicine providers. Matern Child Health J. 2010; 14(6): 922-930.

[63] National Center for Complementary and Alternative Medicine (NCCAM). Director's Page. Josephine P. Briggs, M.D. Childhood Vaccinations - Vital to Our Children's Health. Available at: http://nccam.nih.gov/about/offices/od/2011-03.htm.

[64] Teixeira MZ. Homeopathic use of modern medicines: utilisation of the curative rebound effect. Med Hypotheses. 2003; 60(2): 276-283.

[65] Teixeira MZ. New homeopathic medicines: use of modern drugs according to the principle of similitude. Homeopathy. 2011; 100(4): 244-252.

[66] Teixeira MZ. Homeopathic use of modern drugs: therapeutic application of the organism paradoxical reaction or rebound effect. Int J High Dilution Res. 2011; 10(37): 338-352.

[67] Teixeira MZ. 'New Homeopathic Medicines' database: A project to employ conventional drugs according to the homeopathic method of treatment. Eur J Integr Med. 2013; 5(3): 270-278.

[68] Teixeira MZ. Is there scientific evidence that suppression of acute diseases in childhood induce chronic diseases in the future? Homeopathy. 2002; 91(4): 207-216.

[69] Teixeira MZ. The hygiene hypothesis revisited. Homeopathy. 2005; 94(4): 248-251.

[70] Teixeira MZ. Homeopatia: prática médica coadjuvante [Homeopathy: an adjuvant medical practice]. Rev Assoc Med Bras. 2007; 53(4): 374-376.

\section{Isoprofilaxia não é homeoprofilaxia tampouco imunização homeopática, mas imunização isopática sem fundamentação no modelo epistemológico homeopático: resposta a Golden}




\section{RESUMO}

A homeopatia pode ser empregada na prevenção de doenças epidêmicas (homeoprofilaxia), desde que os medicamentos sejam escolhidos individualmente segundo o princípio da similitude sintomática e em conformidade com a totalidade de sintomas peculiares à epidemia (medicamento do 'gênio epidêmico'), com exemplos seculares descritos na literatura. O uso de nosódios para prevenir doenças epidêmicas (isoprofilaxia), escolhidos segundo o princípio da identidade etiológica, desprezando a individualização sintomática e a experimentação patogenética das substâncias, não tem fundamentação na episteme homeopática. Enquanto não existirem evidências científicas confiáveis que atestem a sua eficácia e segurança, a 'imunização isopática' não pode ser indicada como substituto regular da imunização clássica, infringindo os princípios bioéticos da 'beneficência' e da 'não maleficência'. Apesar de esta prática ser sistematicamente indicada por muitos praticantes da homeopatia, ela é condenada por instituições homeopáticas do mundo todo. Neste artigo, ampliamos a discussão sobre os aspectos epistemológicos, científicos e éticos destas práticas, abordados sinteticamente em revisão anterior.

Palavras-chave: Homeopatia; Promoção da saúde; Prevenção de doenças; Doenças coletivas; Gênio epidêmico; Isoterapia; Vacinação

\section{Isoprofilaxis no es homeoprofilaxis ni inmunización homeopática, sino inmunización isopática y no se fundamenta en el modelo epistemológico homeopático: respuesta a Golden}

\section{RESUMEN}

Homeopatía puede ser utilizada para prevención de enfermedades epidémicas (homeoprofilaxis) siempre que los medicamentos sean escogidos individualmente, de acuerdo al "principio de semejanza sintomática' y a la totalidad de los síntomas característicos de una epidemia dada (remedio del 'genio epidémico'), como demuestran innúmeros ejemplos en la literatura. El uso de nosodes para prevención de epidemias (isoprofilaxis), o sea, escogidos en función del 'principio de identidad etiológica', con total omisión de la individualización sintomática y estudios patogenéticos, no tiene fundamento en el modelo epistemológico homeopático. Hasta que no se disponga de evidencias científicas confiables que atestigüen su eficacia y seguridad, no es posible indicar el remplazo de las vacunas tradicionales por una 'inmunización isopática', pues representaría una contravención de los principios bioéticos de 'beneficencia' y 'no-maleficencia'. Aunque es cierto que muchos homeópatas indican sistemáticamente tal remplazo, éste es criticado por instituciones homeopáticas de todo el mundo. En este artículo, discuto más extensamente aspectos epistemológicos, éticos y científicos de estas modalidades de profilaxis que abordé someramente en una revisión anterior.

Palabras-clave: Homeopatía; Promoción de la salud; Prevención de enfermedades; Prevención y control; Enfermedades colectivas; Genio epidémico; Isoterapia; Vacunas

\section{(c)) BY-NC-ND Licensed to GIRI}

Support: authors declare that this study received no funding

Conflict of interest: authors declare there is no conflict of interest

Received: February 26 $6^{\text {th }}, 2014$; Revised: March $16^{\text {th }}, 2014$; Published: March $30^{\text {th }}, 2014$.

Correspondence author: Marcus Zulian Teixeira, mzulian@usp.br, www.homeozulian.med.br, www.newhomeopathicmedicines.com.

How to cite this article: Teixeira MZ. Isoprophylaxis is neither homeoprophylaxis nor homeopathic immunization, but isopathic immunization unsupported by the homeopathic epistemological model: a response to Golden. Int J High Dilution 
Int J High Dilution Res 2014; 13(46): 54-82

Res [online]. 2014 [cited YYYY Month dd]; 13(46): 54-82. Available from: http:// www.feg.unesp.br/ ojs/index.php/ijhdr/article/view/707/687 